City University of New York (CUNY) CUNY Academic Works

1996

\title{
Study of Volcanic Sediments by Microbeam-PIXE Technique
}

Nazrul I. Khandaker

cUNY York College

M. Ahmed

King Fahd University of Petroleum and Minerals

M. A. Garwan

King Fahd University of Petroleum and Minerals

\section{How does access to this work benefit you? Let us know!}

More information about this work at: https://academicworks.cuny.edu/yc_pubs/79

Discover additional works at: https://academicworks.cuny.edu

This work is made publicly available by the City University of New York (CUNY).

Contact: AcademicWorks@cuny.edu 


\title{
Study of volcanic sediments by microbeam-PIXE technique
}

\author{
N.I. Khandaker ${ }^{\mathrm{a}, *}$, M. Ahmed ${ }^{\mathrm{b}}$, M.A. Garwan ${ }^{\mathrm{c}}$ \\ "Department of Earth Sciences. King Fahd University of Petroleum \& Minerals, Dhatran 31 261, Saudi Arabia

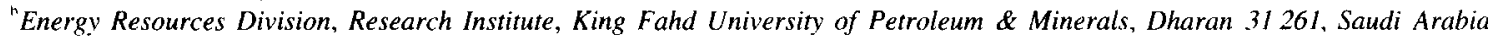 \\ 'Department of Physics, King Fahd University of Petroleum \& Minerals, Dharan 31 261. Saudi Arabia
}

\begin{abstract}
Single mineral grains in a suite of Crelaceous $(85-90 \mathrm{Ma})$ volcanic sedimentary rocks were analyzed using the microbeam-PIXE technique to understand fundamental geological processes responsible for micro-scale variation in elemental composition across mineral zones, twinning, cleavage planes, fractures and grain boundaries. Distributions of major and trace elements show distinct geochemical features indicative of a specific geological setting and a subsequent diagenetic process in these volcanic sediments. Examples of mineral zoning, microstructures of variable chemistry and post-depositional fluid flow are discussed using the data on feldspar group of minerals.
\end{abstract}

\section{Introduction}

Characterization of authigenic minerals that form in response to sedimentary processes provides significant information pertaining to the sedimentary basin in terms of tectonic, thermal and chemical evolution of the associated sedimentary rocks. Detailed chemical and petrological data obtained from these minerals are typically used to discern several parameters including temperature, pressure, fluid composition, oxidation state, $\mathrm{pH}$, etc. These data can be effectively applied to determine $P-T$ (pressure-temperature) pathways of rocks in natural conditions. In addition, they also provide a viable tool for determination of provenance and permit recognizing paleotectonic setting of the sedimentary distributive provinces.

Trace element analysis of single mineral grains, fluid inclusions, mineral zones and matrix phases can help to understand fundamental geological processes responsible for micro-scale variation in geochemistry of the rocks. This in turn can lead to relating the specific geological processes to a particular thermodynamic setting. The data can also be tested against similar natural geological environments.

Proton Induced X-ray Emission (PIXE) spectroscopy has proved to be effective technique for sensitive and accurate analysis of major and trace elements in mineral samples [1,2]. Microbeam-PIXE has recently added a new dimension to research in geological science by allowing measurements of trace element distributions at a spatial resolution of a few $\mu \mathrm{m}$ [3]. Because of its high elemental detection sensitivity (at ppm levels), microbeam-PIXE has

* Corresponding author. Fax +99638602595. a distinct advantage over competing Scanning Electron Microscopy (SEM).

\section{Method}

\subsection{Sample preparation}

Polished thin sections (about $30 \mu \mathrm{m}$ ) of lithified samples were prepared by standard techniques and mounted on petrographic slides with epoxy resin. The thickness of the samples was dictated by the requirement of petrological microscopes which were used to record relevant mineralogical and petrographical characteristics, and to mark areas of interest for micro-PIXE analysis. This thickness was also just about enough to stop $2.5 \mathrm{MeV}$ protons or reduce their energy to an extent making them unproductive to generate $\mathrm{X}$-rays from high $Z$ traces, if any, in the glass mounts. For micro-PIXE analysis, the samples were coated with a thin layer of carbon to make the surfaces electrically conducting. The carbon layer was too thin to have any significant effect on PIXE measurements.

\subsection{Analysis}

The scanning proton microprobe at the Energy Research Laboratory (ERL) of the Research Institute of King Fahd University of Petroleum \& Minerals (KFUPM) was used to carry out the measurements reported in this paper. The ERL microprobe facility has been described elsewhere [4,5] and some of its applications have been reported recently [6-8]. Typical spatial resolution of the microbeam for $2.5 \mathrm{MeV}$ protons is about $4 \mu \mathrm{m}$ at a current of about 


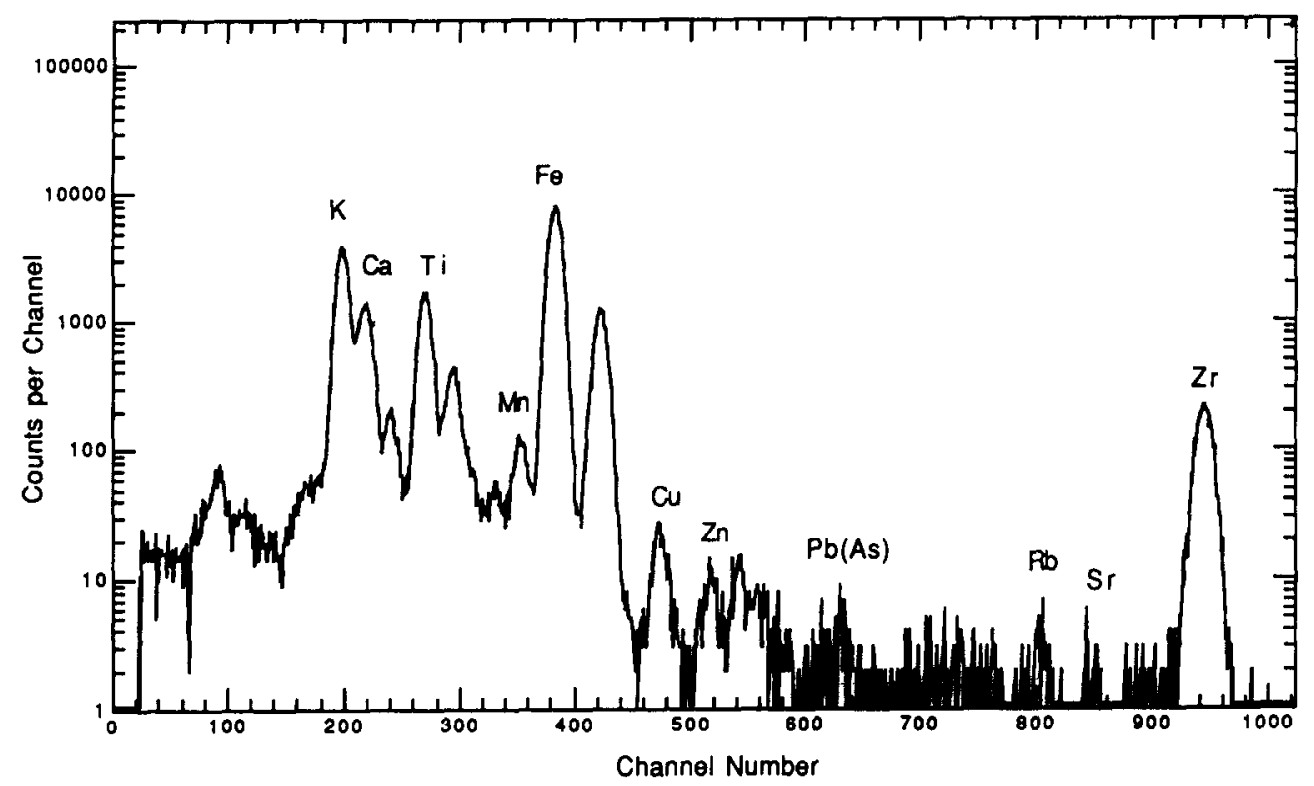

Fig. 1. A typical micro-PIXE spectrum averaged over the scanned area of $540 \mu \mathrm{m} \times 540 \mu \mathrm{m}$ on a feldspar grain at $E_{\mathrm{r}}=2.5 \mathrm{MeV}$ showing the presence of several trace elements.

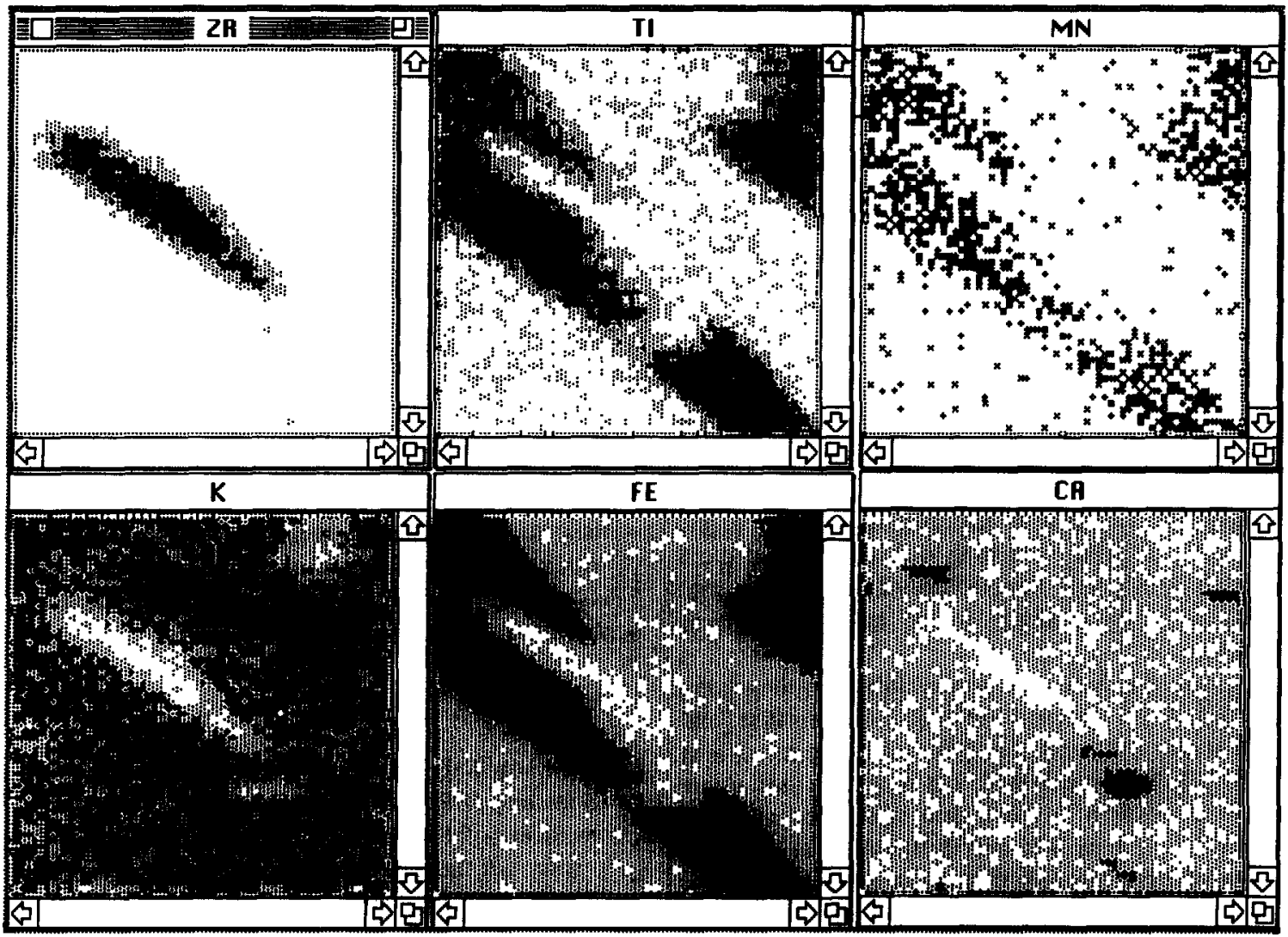

Fig. 2. Elemental distribution maps from $540 \mu \mathrm{m} \times 540 \mu \mathrm{m}$ area inside a feldspar grain showing microstructures having distinct spatial variations in chemistry. 
$50 \mathrm{pA}$ and the maximum scanning range is $540 \mu \mathrm{m}$ in each of the $X$ and $Y$ directions. A secondary electron detection system was used to quickly position the microbeam on any region of interest on the sample for subsequent PIXE analysis. From the scanned area of the sample, an average elemental composition spectrum as well as multiple elemental distribution maps have been produced simultaneously.

\section{Results and discussion}

Thirty seven samples of various mineral phases including feldspar, pyroxene, amphibole, biotite, chlorite and magnetite were studied. Results of these analyses show distinctive microtextural and micromorphological features associated with volcanic sediments. Some of these features will be illustrated here by using the data on the feldspar group of minerals. Fig. 1 shows a typical PIXE spectrum averaged over the scanned area of a feldspar grain. Although no absolute elemental concentration data could be made available, estimations relative to major constituents ( $\mathrm{K}$ and $\mathrm{Ca}$ ) indicate the presence of several trace elements ( $\mathrm{Rb}, \mathrm{Sr}, \mathrm{Zr}$, etc.) in these samples. Detection of such trace elements in single mineral grains provides an important tool to study chemical alteration in volcanic sediments after their deposition. Some of these traces such as $\mathrm{Zr}$ are immobile and resistant to changes in diagenetic environment [9-11]. These immobile trace elements can therefore serve as index to the original chemistry of the volcanic sediments [12-14]. In contrast, many of the major constituents are mobile and can easily be removed from or added to the volcanic sediments, thereby altering the original mineralogy and creating a problem in interpretation of geological data on volcanic sediments [15-17]. Trace element data on geological samples are therefore very useful. In this respect, the PIXE technique, being sensitive to trace element detection, has an important advantage over other analytical techniques including electron microscopy for the study of geological samples.

Morphology of volcanic sediments are determined by several physical-chemical factors including depth of burial, post-depositional fluid flow, chemistry of the diagenetic fluid, original composition of the parent constituents, Eh$\mathrm{pH}$ of the diagenetic fluid, and post-depositional tectonic overprinting. Elemental distribution maps measured in the feldspar specimen (Figs. 2-4) show evidence of some of these influences on volcanic sediments. Maps in Fig. 2,

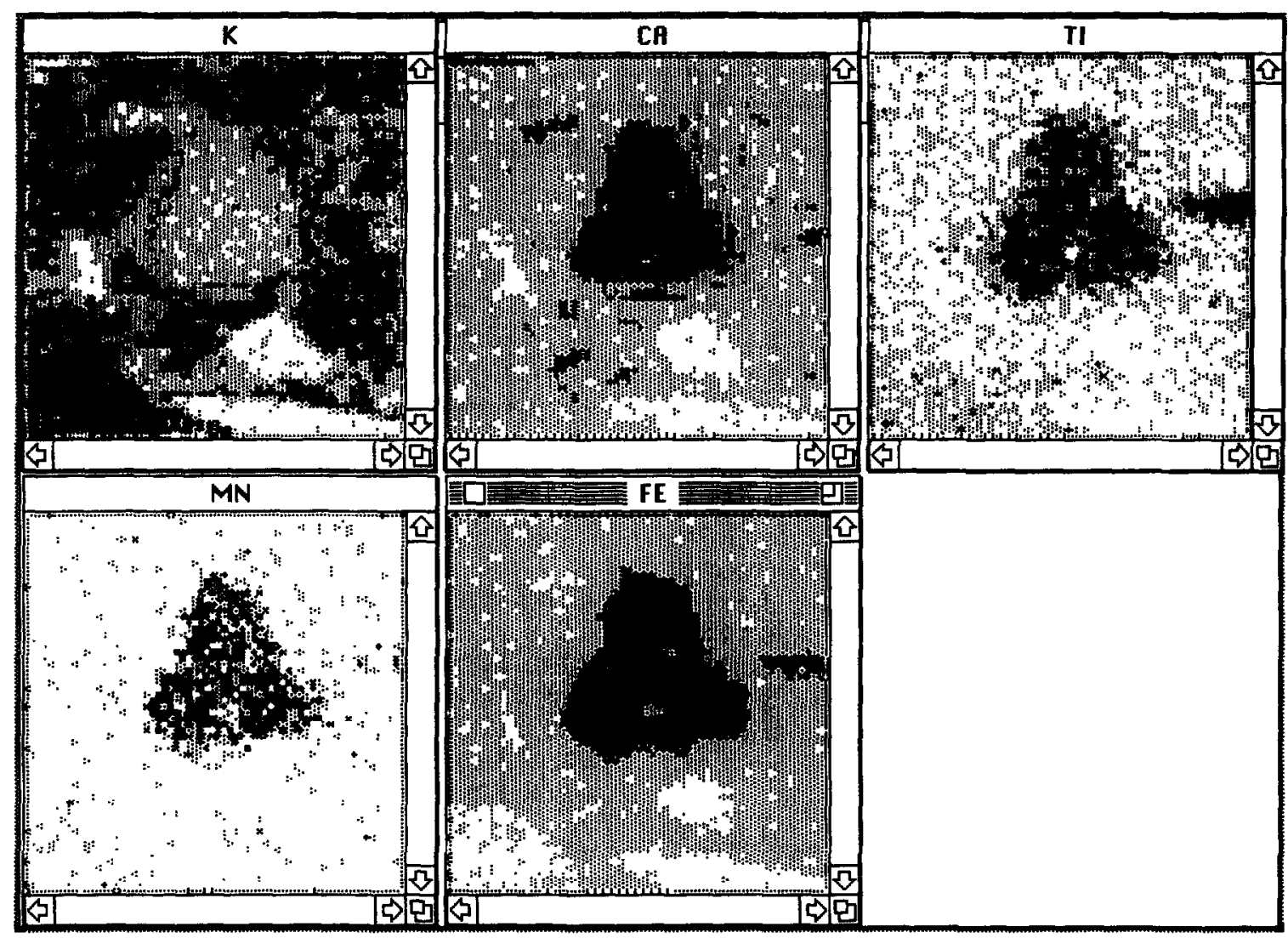

Fig. 3. Elemental distribution maps from $540 \mu \mathrm{m} \times 540 \mu \mathrm{m}$ area encompassing a small feldspar gxain showing an example of normal zoning. 


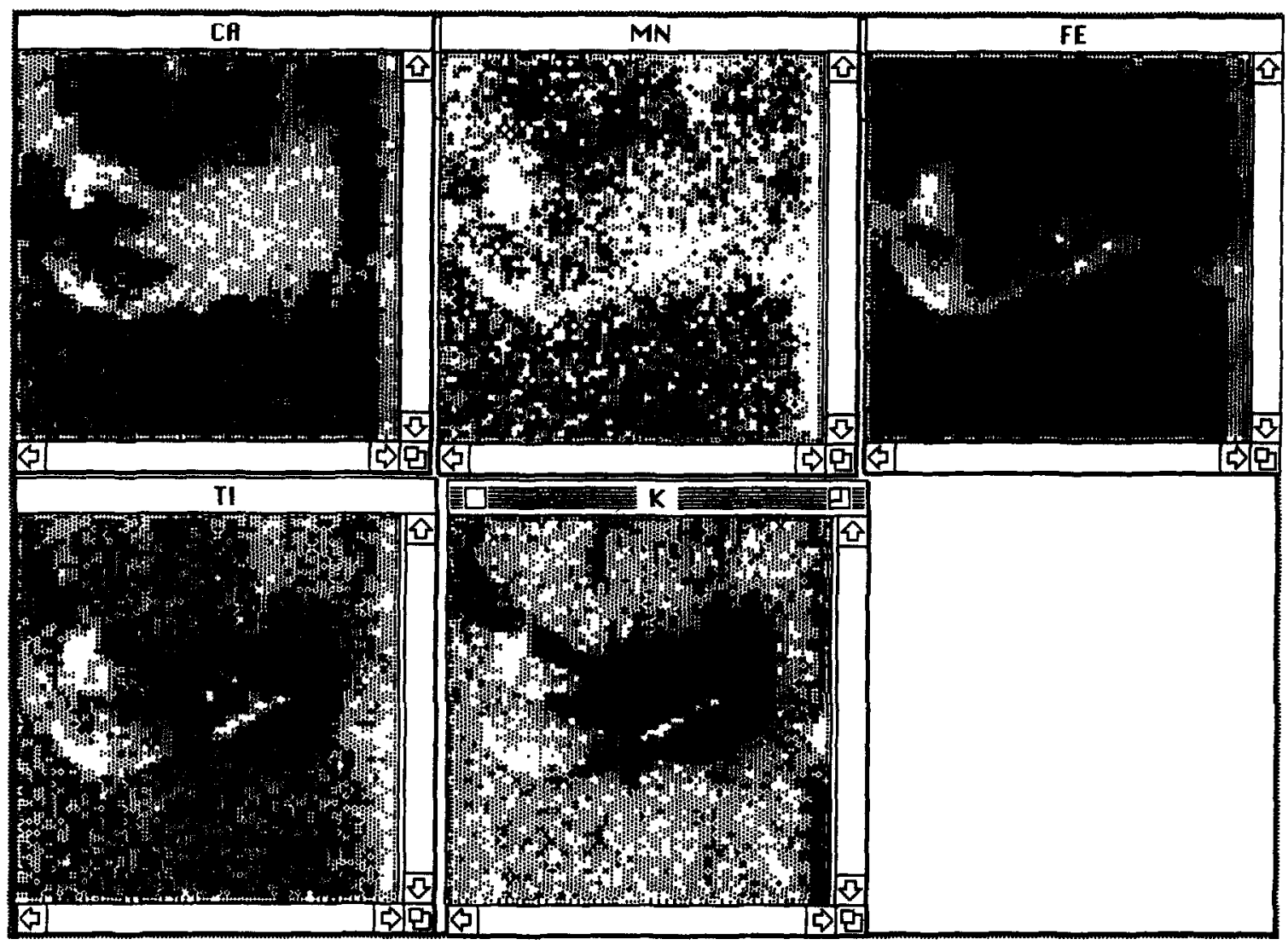

Fig. 4. Elemental distribution maps from $540 \mu \mathrm{m} \times 540 \mu \mathrm{m}$ area inside a feldspar grain showing a case of post-depositional fluid flow.

obtained from an area of $540 \mu \mathrm{m} \times 540 \mu \mathrm{m}$ within a feldspar grain, show some of the microstructures of the grain. Presence of trace element $\mathrm{Zr}$ is anticorrelated with the major elements $\mathrm{K}, \mathrm{Ca}, \mathrm{Ti}, \mathrm{Mn}$ and Fe. This clear chemistry variation within the grain can be attributed to temperature effects which cause elements to segregate and crystallize at different regions. Fig. 3 maps encompassing a small feldspar grain show an example of normal zoning where the core consisting of primary elements $\mathrm{Ca}$ and $\mathrm{Fe}$ is surrounded by a secondary element K. Maps in Fig. 4 display the case of post-depositional fluid flow through microfractures and remobilization of secondary elements with the fluid flow. Individual maps in this figure show that the primary elements, $\mathrm{Ca}, \mathrm{Mn}$ and $\mathrm{Fe}$ are completely or partially flushed out from the core by the secondary elements $\mathrm{K}$ and $\mathrm{Ti}$ brought in by the incoming diagenetic fluid.

\section{Conclusions}

Present study on volcanic sediments with microbeamPIXE technique shows the following geological and geochemical features:
- Mineral zones are very pronounced in the feldspar group of minerals, particularly in Ca-rich feldspars.

- There are microstructures within a grain having distinct variations in chemistry.

- There is a strong evidence of post-depositional fluid flow through microfractures.

- Presence of immobile traces like $\mathrm{Zr}$ along with petrological data support an intermediate type volcanic provenance nearby for these suite of sediments.

\section{Acknowledgements}

The authors would like to thank the management of the Energy Resources Division of the Research Institute of this University for permission to use the microbeam-PIXE facility. Thanks are also due to personnel in Earth Sciences Department for their help.

\section{References}

(1) S.H. Sie, W.L. Griffin, C.G. Ryan, G.F. Suter and D.R. Cousens, Nucl. Instr. and Meth. B 54 (1991) 284. 
[2] F. Watt, G.W. Grime and D.G. Fraser, in: F. Watt and G.W. Grime, eds., Principles and Applications of High Energy Ion Microbeams (Hilger, Bristol, 1987) pp. 239-272.

[3] P. Bruckschen, F. Bruhn, J. Meijer. A. Stephen. D.K. Richter and J. Veizer, Proc. Int. Conf. on Microprobe Technology and Applications, Shanghai, China, 1994, Nucl. Instr. and Meth. B 104 (1995) 427.

[4] M. Ahmed, J. Nickel, A. Hallak, R. Abdel-Aal, A. Coban, H. Al-Juwair and M. Aldaous, Nucl. Instr. and Meth. B 82 (1993) 584

[5] M. Ahmed, J. Nickel, A. Hallak, R. Abdel-Aal, A. Coban and M. Garwan, Technical Report, RI II-BAP-32, 1993.

[6] J. Nickel, M. Ahmed and M. Garwan, presented at Int. Conf. on Microprobe Technology and Applications, Shanghai, China, 1994.

[7] M. Ahmed, A. Rahman, J. Nickel and M. Garwan, presented at Int. Conf. on the Application of Accelerators in Research and Industry, Denton, TX, USA, 1994.
[8] A. Rahman, M. Mohamed and M. Ahmed, Applied Catalysis 121 (1995) 203

[9] N.I. Khandaker, C.F. Vondra and K.E. Seifert, Am. Assoc. Petroleum Gcologists Bull. 3 (1994) 186.

[10] N.I. Khandaker, Int. Geological Congress 2 (1989) 183.

[11] N.I. Khandaker, C.F. Vondra and K.E. Seifert, Soc of Economic Paleontologists and Mineralogists (SEPM) Vol. 5 (1988) pp. 28-29.

[12] R.W. Kay, Ptill. Trans. Soc. London, Ser. A 310 (1984) 535.

[13] M. Meschede, Chem. Geology 56 (1986) 207.

[14] J.A. Pearce and M.J. Norry, Contrib. Mineralogy and Petrology 69 (1979) 33.

[15] P.E. Potter, N.F. Shimp and J. Witters, Geochimica Cosmochimica Acta 27 (1962) 669.

[16] A.D. Saunders, Geological Soc. of London, Special Publ. 16 (1984) 59.

[17] J.A. Winchester and P.A. Floyd, Chemical Geology 20 (1977) 325 . 